\title{
THE ROLE OF GIS IN ADDRESSING ENVIRONMENTAL, SOCIAL AND TOURISTIC CHALLENGES IN MOHAMMEDIA CITY, MOROCCO
}

\author{
Mohamed Rabii SIMOU ${ }^{a}$, Hassan RHINANE ${ }^{a}$, Mehdi MAANAN ${ }^{\mathrm{a}}$ \\ ${ }^{a}$ Geosciences Laboratory, Faculty of Sciences-Ain Chock, Hassan II Univertsity, Casablanca, Morocco
}

Commission 4, WG 7

KEY WORDS: WWTP, GIS, RS, LU, GPS, MCDA

\begin{abstract}
During the last years, Morocco's Environmental, Social and Touristic perspectives has improved significantly, but it remains one of the biggest challenges for Mohammedia city. The purpose of this study is to locate an optimal site for the construction of a new Waste Water Treatment Plant (WWTP) in order to help the environment, to select an appropriate site for the construction of a new School that will benefit the social needs of the city and to create a suitable tour plan of touristic sites for tourism. It was carried out by using Geographic Information System (GIS), Remote Sensing (RS), Global Positioning System (GPS) devices, Digital cameras and Multicriteria Decision Analysis (MCDA).Throughout the process, the used data for both WWTP and School selection include the remote sensing data of multi spectral satellite imageries and the digital elevation model combined with vector data of land use (LU) layers, and for Tour creation the used data include collected photographs and GPS data from the site. According to MCDA, the results presents an optimal site with an area of $48283,02 \mathrm{~m}^{2}$ for a new WWTP, a suitable area with an area of $3200 \mathrm{~m}^{2}$ for a new School and a city tour for tourists with a distance of $27 \mathrm{~km}$.
\end{abstract}

\section{INTRODUCTION}

Morocco's Enviromental, Social and Touristic parts are improving day by day, but still there are many challenges to overcome in cities like Mohammedia city. The great environmental issues are worldwide, it includes damages of the natural environment and environmental pollutions. Moreover, it has been realized the growthof urban population and human activities are caused many environmental issues especially in the urban areas. However, that the situation of the environment in the urban areas gets worse, which leads detrimental influences against the human beings. The sewage treatment issue is one of the main problems in many cities worldwide and it getting worse recently in different regions. In order to solve the sewage treatment issue, building efficient and practical sewage treatment plant is a good way to treat polluted water (Abdalla, O. O. and El Khidir, S. O., 2017).

Since 1956, when Morocco achieved independence, the social part has been evolving, the education issues is one of the main problems that needs more improving, the education system has been the subject of endless discussion and controversy in a wide range of national forums. So much so, that from 1956 to 1977 , Morocco had some twenty ministers of education (Llorent Bedmar, V., 2014), and the changes at the top led to a certain instability and lack of continuity in education policy. The disagreements over the measures to be adopted contrast with the unanimity in their diagnosis of the problems, namely: the uncontrolled growth of students in secondary and higher education, lack of equipment, poor quality all of that leads to searching for optimal solutions so as to build a safe environment for the students with the respect of criteria given.

Tourism has long been an important sector for Morocco. As early as the beginning of the 20th century, Morocco was positioned as a tourism destination for the people of France. Today, the sec- tor has been identified by the Moroccan government as one of five priority sectors for the country to develop. Indeed, Moroccohas several natural advantages that position it well to competein tourism. These advantages include a highly diverse landscape including extensive mountain ranges, forests, and coastline ex- tremely pleasant climate, and widespread knowledge of French among the population, making Morocco a natural vacation destination for the residents of France (Porter, M. and Ketels, C., 2008).

That's why in this study the main focus is to present different solutions of different challenges that can overcome some issues of the city and that can help Mohammedia benefits from it.

\section{MATERIALS AND METHODS}

\subsection{The Study Area's setting}

Mohammedia lies along the Atlantic Ocean 24 kilometres (15 miles) northeast of Casablanca. It is located between the outlets of the rivers Oued El-Maleh and Oued Nfifikh and is bordered by the Atlantic Ocean to the north, Ben Slimane Province to the east and south, and the prefecture of Sidi Bernoussi-Zenata to the west. Geographically, it located between $33^{\circ} 41 \mathrm{~N}$ and $7^{\circ} 23 \mathrm{~W}$. The total area is $33,76 \mathrm{~km}^{2}$ approximately (Figure 1).

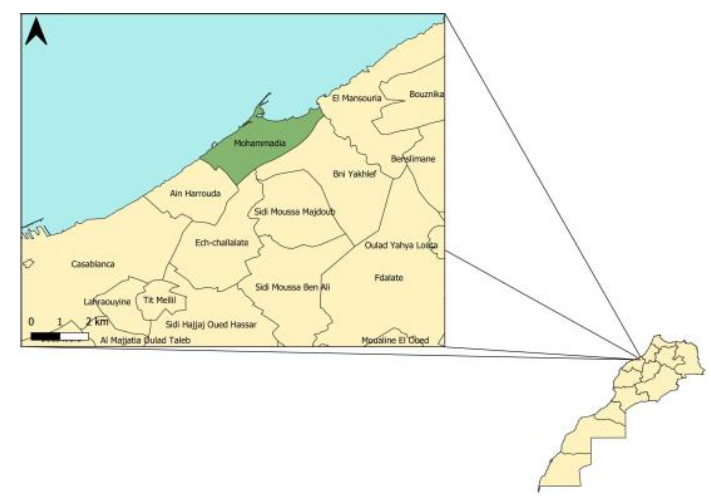

Figure 1. Study area location 
Mohammedia has a hot-summer Mediterranean climate (Köppen climate classification Csa), the period of November through April is mild and rainy with average high temperatures of 17 to $21^{\circ} \mathrm{C}$ and lows of 8 to $12{ }^{\circ} \mathrm{C}$, however temperatures can occasionally drop to around $2{ }^{\circ} \mathrm{C}$ in the morning, or be as high as $24^{\circ} \mathrm{C}$ for a few days during winter, and the period of May through October is warm to hot and dry with average high temperatures of 22 to 26 ${ }^{\circ} \mathrm{C}$ and lows of 15 to $20{ }^{\circ} \mathrm{C}$, but temperatures can exceed $32{ }^{\circ} \mathrm{C}$ and occasionally reach $40^{\circ} \mathrm{C}$. Most rainfall occurs from November to April, and the average annual precipitation is around 432 $\mathrm{mm}$ (Figure 2).

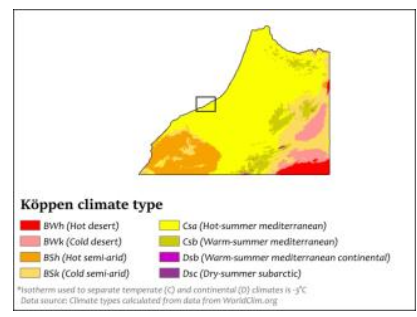

Figure 2. Climate type of Mohammedia

The population of Mohammedia is growing at a fast rate. The city, which had a population of only 500 people in 1914 , is currently home to about 204,000 people. The population of the prefecture of Mohammedia is estimated at 336,000 inhabitants with an average population density of 5,000 inhabitants per square kilometer $(13,000 / \mathrm{sq} \mathrm{mi})$, it's a relative variation of $25.6 \%$ and an average annual growth rate (TAAM) of $2.3 \%$ during the period 2004-2014 (Figure 3).

\begin{tabular}{|c|c|c|c|c|c|c|}
\hline \multirow[b]{2}{*}{ 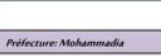 } & \multicolumn{2}{|c|}{${ }_{\text {itton }}^{2004}$} & \multicolumn{2}{|c|}{2014} & \multicolumn{2}{|c|}{ 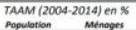 } \\
\hline & 322286 & asost & Sor 648 & 96351 & 230 & 391 \\
\hline Mohummodidathan & 788679 & 39154 & 208612 & 49974 & tor & 247 \\
\hline An Herround atan, & 4858 & 8417 & 62420 & tstos & $\operatorname{tas}$ & sos \\
\hline CR Bnivether & $3 m m_{2}$ & 6687 & $483 x g$ & ${ }_{10837}$ & 396 & 495 \\
\hline 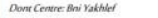 & 11+80 & 2205 & 19970 & 4215 & 157 & 627 \\
\hline 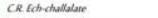 & 36922 & 7264 & 535003 & 12800 & $x z$ & sab \\
\hline 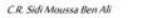 & 93668 & 1666 & $11+45$ & 2650 & 202 & 475 \\
\hline 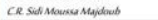 & 12412 & 2502 & 20330 & 4917 & ses & 699 \\
\hline Région Grand Cassablanca & 3631061 & 762242 & 4270750 & 1032576 & 1.64 & sos \\
\hline 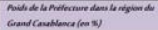 & ${ }_{a s e s}$ & ase & Q47 & $2 x$ & . & . \\
\hline
\end{tabular}

Figure 3. Population growth in prefecture of Mohammedia

\subsection{Methodology}

The methodology that has been chosen for this study includes three main themes, each project has followed a different methodology.

- Environment: Rivers in Mohammedia are constantly polluted by the water wasted which is why the project of the construction of a new WWTP has been chosen it would preserve the natural resources of the city and it would benefit the city by reusing the water in agricultural fields.

- Social: The fast growth of the population should help the city realize that the need of new schools that means the development of a standardized set of criteria for safe schools which led to search for an optimal site to build a new school.

- Tourist: The touristic part it's important to benefit economically Mohammedia that means planning for a tourist tour map in order to promote the city for new tourists.

\subsubsection{Environmental}

A number of factors were taken into consideration in order to locate a suitable site for the construc- tion of the wastewater treatment plant, such as climate, soil tex- ture, permeability, and social and economic parameters. Becauseof the limitations in the methods and data gathering processes, it was not possible to include all of the parameters in the mod- els. Throughout the present study, three groups of data, includingthe environmental, geological, and economic criteria and severalparameters, were used for selecting a suitable location for con- struction of wastewater treatment plant (Figure 4).

Multi-Criteria Decision Analysis The decision-making process begins with the recognition of the problem to be decided. In the intelligence phase, a situation is examined for conditions calling for a decision. In the design phase, decision makers develop alternative solutions to the decision problem already identified. Typically, a formal model is used to support a decision maker in determining the set of alternatives. In the choice phase, decision makers evaluate the decisions and choose the best alternative. In the context of decision problems with a spatial connotation, the potential for application of spatially enabled methods in Simon's decision phases has already been examined. While the intelligence and design activities can mostly be covered by multipurpose spatial analysis methods, the choice phase requires specific methods still absent from most GIS.

In general, a GIS has three main components and is a computer system that includes hardware, software and appropriate procedures (or techniques and orders for task implementation). In addition, GIS are distinguished by their use of spatially (geographically) referenced data, and for carrying out various management and analysis tasks on these data. By allowing data to be organised, presented and analyzed efficiently, by integrating them with other data and by the creation of new data that can be operated on in turn, GIS creates useful information $t$ which can help decision making. Geographical information can be defined as georeferenced data that has been processed into a form that is meaningful to the recipient decision-maker and which is of real or perceived value in the decision-making process. In general, the MCDA in GIS should be viewed as a process of conversion of data to information that adds extra value to the original data (Drobne, S. and Lisec, A., 2009).

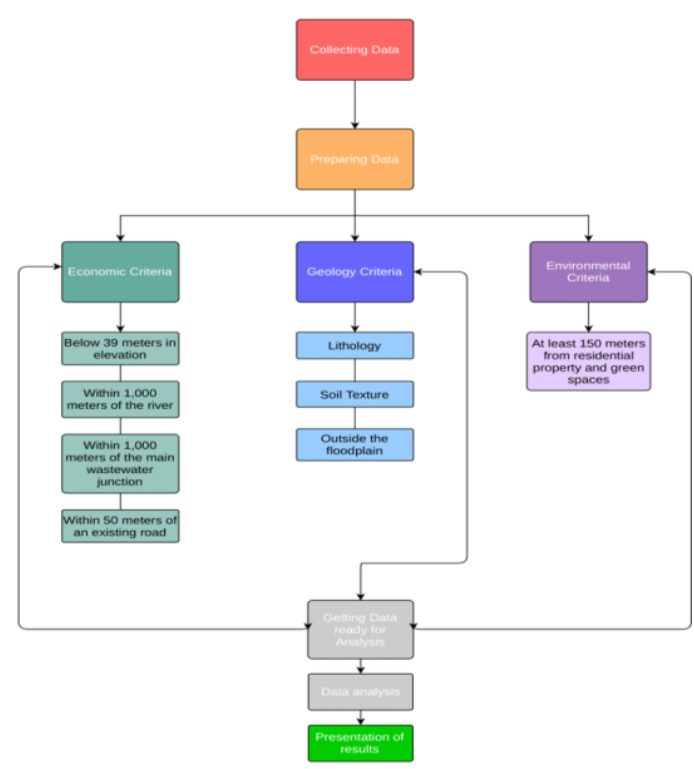

Figure 4. Environmental Methodology 


\subsubsection{Social}

The aim of this research is to select the suitable site for a new school, after criteria were identified in this study both raster and vector data were obtained. They were obtained from websites and others were generated from the existing maps.WLC and AHP were employed as an ideal method for tackling spatial multi attribute decision making and the multi attribute procedure was based on concept of weighted average. The weight ofeach criterion is determined by using AHP techniques, then theentire criteria were rasterized after assigned the value of relative importance to each attribute and overlaid in the weight overlay tool.

Therefore, the results of weight overlay of all combined criteria will be suitable areas with their classes according to their suitability. The higher value indicates the most suitable while the lower value is less suitable and areas marked as restricted have a value of zero. Then proceeded by selecting the optimal area, in this study the criteria include the following: Distance from Existing Schools, Landuse Map, Elevation, Near to Roads, to Recreation sites and to Destination (Figure 5).

Weight Linear Combination The most prevalent procedure for multi-criteria evaluation is the weighted linear combination. With a weighted linear combination, factors are combined by applying a weight to each followed by a summation of the results to yield a suitability map: i.e.,

$$
s=\sum w_{i} x_{i}
$$

where $\mathrm{S}$ is suitability, $\mathrm{w}$, is the weight of factor $\mathrm{i}$, and $\mathrm{x}$, is the criterion score of factor $i$.

This procedure is not unfamiliar in GIS and has a form very similar to the nature of a regression equation. In cases where Boolean constraints also apply, the procedure can be modified by multiplying the suitability calculated from the factors by the product of the constraints: i.e.,

$$
S=\sum\left(w_{i} x_{i}\right) \pi c_{j}
$$

where c, is the criterion score of constraint I and II is the product. All GIS software systems provide the basic tools for evaluating such a model. In addition, in IDRISI, a special module named MCE has been developed to facilitate this process. The primary issues, however, relate to the standardization of criteria scores and the development of the weights (Articte, P. N., 1995).

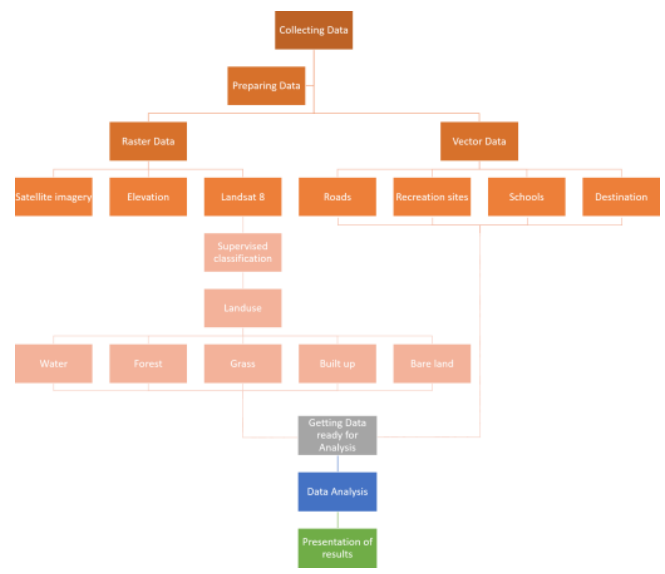

Figure 5. Social Methodology

\subsubsection{Touristic}

The purpose of this study is to plan a city tourist tour of Mohammedia, raster, GPS and vector data were obtained for this project. They were obtained from websites, devices and others were generated from the existing maps. A Multi-Scenario Analysis has been done in order to obtain an op-timal route to visit all the Tourist sites. In this study the criteria include the following: Finding monumental, nature, educational,art, sports, leisure and industrial sites, and finding an optimal road to visit all the sites (Figure 6).

Optimal Tour the method used in order to create an optimal tour started with data collection, data processing and analysis. Data collection process was documented with the researches used to collect useful data for analysis. It provided an overview of the project and explained the analysis. The use of application of GIS in the study provided innovative analytical method, GIS, in tourism field can bridge the gap between tourism study and the use of technologies.

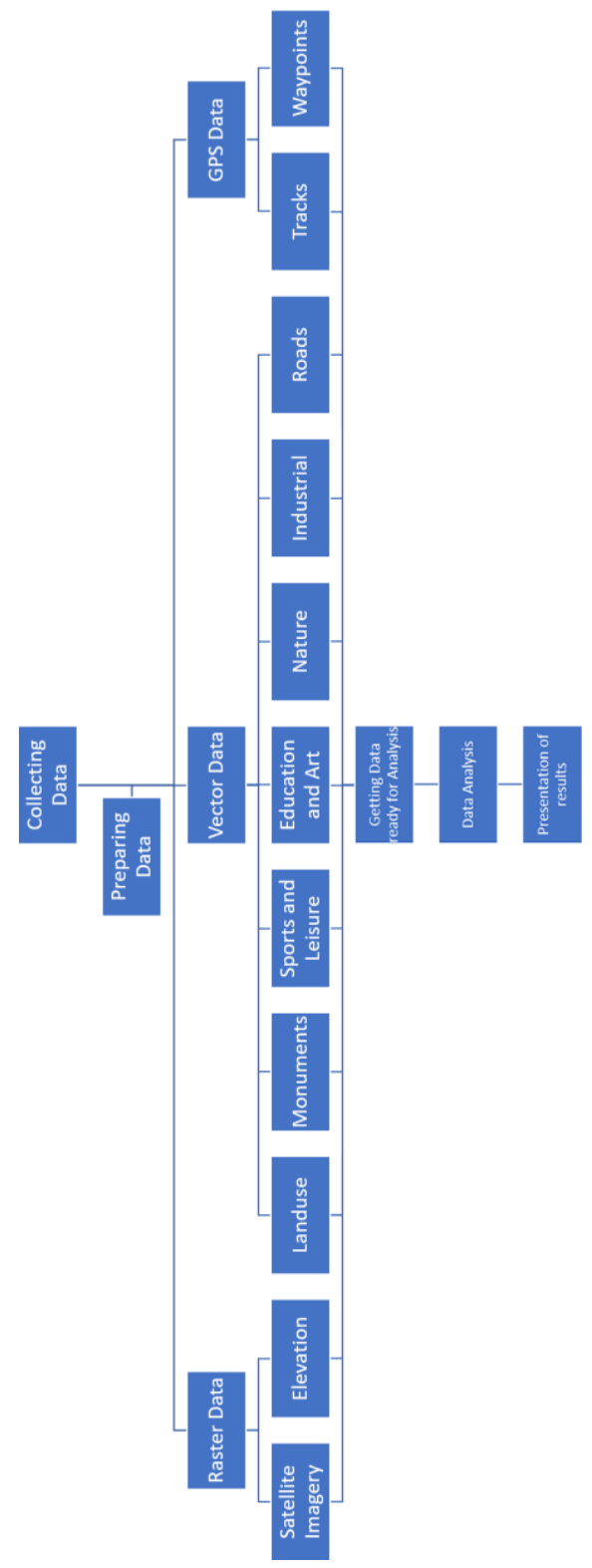

Figure 6. Touristic Methodology 


\section{RESULTS AND DISCUSSION}

\subsection{Environmental}

This study it was evaluated with the multi-criteria decision-making process. The results of decision making are related to the problem (criteria, choices and limitations) and rate of errors in data and uncertainty, considering this method on place of stations, accurate evaluation of methods and choosing the most appropriate location for project is one of the most important problems of decision makers. In this study proper criteria for construction of wastewater treatment station, is specified by consulting expert's wastewater treatment company and by considering existing data. In the final results, two sites have been found one suitable site with an area of $48283,02 \mathrm{~m}^{2}$ and the other one is an unsuitable site with an area of 17495,51 $\mathrm{m}^{2}$ (Figure 7).

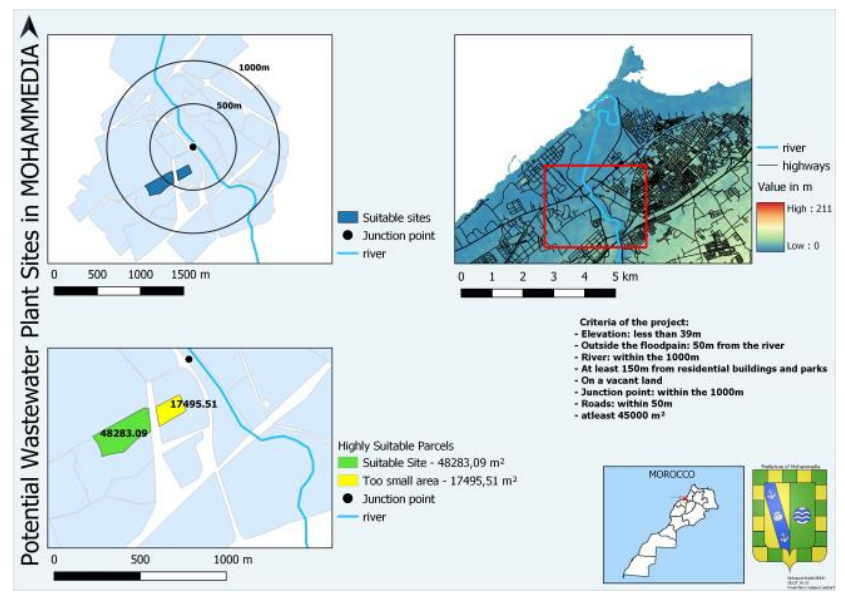

Figure 7. Potential Wastewater Treatment Plant in Mohammedia

\subsection{Social}

The aim of this study was finding a suitable site for a new school in Mohammedia city. The potential sites should have appropriate safety criteria in order to provide a safe school for children near to leisure places and to a road for safe transportation. Many parameters contributed to safe location were identified.

In this study, approximately 26 hectares of the potential areas were identified as suitable areas, all of them are near to Oued el maleh river (Figure 6).

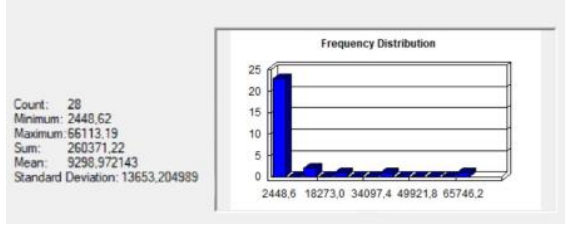

Figure 8. Potential areas for a new school

In the final results (Figure 7), one suitable site with an area of approximately $3200 \mathrm{~m}^{2}$ was obtained from the models it's the closest one to the destination layer. The other areas either have less than $2000 \mathrm{~m}^{2}$, or farther than the destination.

For the Zone Management Plan, the suitable site is located in the zone B3s2 which is a zone that accept all kind of activities and it is possible to build a ground floor +3 floors which is very good for a school.

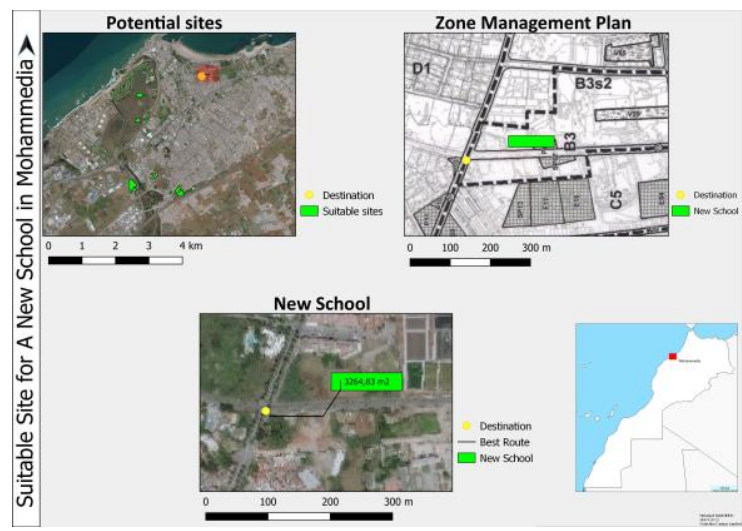

Figure 9. Suitable Site for a New School in Mohammedia

\subsection{Touristic}

The aim of this study is to show the benefits of a GIS in tour planning which include faster and optimal decision making leading to increased efficiency, Savings time that would have been lost in taking more time-consuming routes. It helps also preserving of resources like petroleum that would have been burnt in taking longer routes, in addition to the extra carbon dioxide that would have been emitted into the atmosphere which is bad for the global warming and other undesirable environmental effects. Also, to show the most important tourist sites in Mohammedia city which will help people knowing more about the city and thehistory of the city.

In the final result, it was presented as a simple Tourist Map Tour Map that has a Time Estimation for the Route in order to help Tourist know how much time is between each destination on a Vehicle and table of the total distance, time taken at each destination and total time estimation of the day (Figure 6), And finally a visit has been done for each site to verify the tour and the suitability of the environmental and social sites.

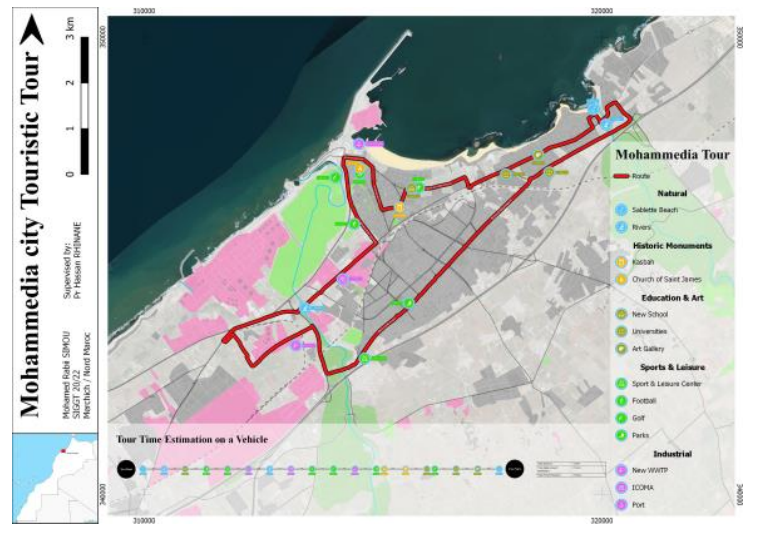

Figure 10. Mohammedia city Touristic Tour

\section{CONCLUSION}

To conclude Mohammedia city and many other cities are trying to overcome many challenges nowadays, in order to do that there are many tools that have proven effective in many countries one of them is GIS, GIS has helped in a lot of fields, one of those fields are the environmental, social and tourist fields that is why this project tried to show how GIS can be really important in saving the environment and benefiting cities in the future. 


\section{REFERENCES}

Abdalla, O. O. and El Khidir, S. O., 2017. Site selection of wastewater treatment plant using rs/gis data and multi-criteria analysis (mca): Case study omdurman city, khartoum state, sudan.

Articte, P. N., 1995. Raster procedures for multi-criteria/multiObiective decisions. Photogramm. Eng. Remote Sens 61(5), pp. 539-547.

Drobne, S. and Lisec, A., 2009. Multi-attribute decision anal- ysis in gis: weighted linear combination and ordered weighted averaging. Informatica.

Llorent Bedmar, V., 2014. Educational reforms in morocco: Evolution and current status. International Education Studies, 7 (12), 95-105.

Porter, M. and Ketels, C., 2008. Analysis of the moroccan tourism cluster. Microeconomics of Competitiveness Country Competitiveness Project. Morocco, Rabat pp. 31-37. 